\title{
University- Industry Collaboration: A Case Study of a Research Programme
}

\author{
Jorge Afonso ${ }^{1}$ and Fernando Romero ${ }^{2}$ \\ ${ }^{1}$ Bosch Car Multimedia, Braga, Portugal \\ ${ }^{2}$ University of Minho, Guimarães, Portugal \\ pg31491@alunos.uminho.pt \\ fromero@dps.uminho.pt \\ DOI: 10.34190/EKM.20.230
}

\begin{abstract}
University-industry collaborations are widely seen as an important mode of institutional interaction and technology transfer. Although there is now a considerable amount of research concerning this phenomena, there are surprisingly few inner studies of collaboration programmes between a university and a firm. The present work presents the results of a study of a large research programme that involved the collaboration of a university and a local branch of a large multinational firm that manufactures electronic components for the automotive sector. The research strategy is based on a qualitative case study approach. Data collection was made through secondary sources and through extended interviews with people at three hierarchy levels of the collaboration. The interview questions and themes were based on selected factors that the literature referred as affecting positively or negatively the research collaborations between university and industry. The aim was to confirm the hypothesis advanced by the literature and/or identify additional factors that could be important determinants of the relationship. The results seem to show that factors like communication, team spirit, researchers' recognition, institutional bureaucracy and organizational issues may be elements which can alter or improve the collaboration.
\end{abstract}

Keywords: university-industry collaboration, research programme, success factors

\section{Introduction}

There has been a growing trend in collaboration between industrial organizations and universities (Dooley \& Kirk, 2007). For technology companies, innovation must be a constant to keep pace with the times. Without often having the capacity and knowledge to take this step with the desired success, they seek these skills at university. The two institutions have common interests, but they do have interests that are sometimes conflicting due to their different cultures and mind-sets. For the process of joint cooperation and learning to take place, both in the business and academic spheres, it is necessary to foster an environment conducive to relations between the various institutions/actors (Mussi, Pedroso and Stoeckl, 2017), which involves several factors.

Among the motivational factors, the previous successful links, the reputation of the partner, the definition of objectives and the geographic proximity stand out. As for organizational factors, the trust between the parties, the flow of information, the commitment and the relationships of dependence between those involved, in view of the objectives set for the interaction (Mussi and Segatto, 2013), stand out.

Collaboration may involve a programme of which a number of individual projects financed by companies or governments themselves are part. In this article, a case consisting of a collaboration programme, defined as a group of projects and subprograms, between a university and a company, financed mainly by the Portuguese state within the framework of European Union structural funds programmes, is analysed in an exploratory manner.

\section{Objectives}

This research project aims to contribute to a better understanding of how a University-Industry (U-I) collaboration works in a context of an innovation programme management.

It is expected to understand the limitations, challenges, barriers, advantages and benefits it can bring for both parties. It is also expected to understand how these factors may be related to organizational difficulties.

The literature refers to many conceptual aspects of these topics and presents some empirical studies, most of them based on questionnaires. However, studies focusing on concrete university-industry collaboration projects are not very common. Studies on collaborative programmes are even less common. Thus, the aim of this study 
is to contrast the ideas expressed in the literature with the results of a specific case study on a collaborative programme between a university and a company, and to try to explore some implications in terms of management and organisation of U-I collaboration.

\section{Literature review}

In this section a concise review of the literature will be made, pointing out some of the main ideas and theories regarding collaboration between university and industry that are more directly linked to the above research objectives. The results of the case study will be analysed in the light of these concepts.

\subsection{Motivation}

According to (Anatan, 2015) the theoretical explanation that leads organizations to decide to cooperate has to do mainly with pressures from the external environment that demand more innovation capacity, resulting from $R \& D$, in order to become more competitive.

In the collaboration between University and Industry (U-I), there are complementarities that can be explored. Companies are interested in commercialising scientific knowledge, academics generally do not have this ability to turn knowledge into useful technology (Poyago-Theotoky, Beath and Siegel, 2002).

Large companies seek long-term competitive advantages in customer relations and future business opportunities, while small companies generally seek direct and immediate benefits such as production/technology optimization, resource sharing and reputation management (Lam, Hills and Ng, 2012).

Universities cooperate with industry may lead to co-publishing results of joint research (Yegros-Yegros, et al., 2016). Collaborations are generally sustainable when partners allow their common objectives to be met at the same time as achieving their individual objectives (Lee, 2000).

\subsection{Success factors}

Success factors can be tentatively classified into two categories: organizational and contextual factors (Sánchez and Valentín, 2006). Organizational factors include commitment, communication, trust, conflict and dependency. Contextual factors are the previous links, reputation, clear definition of objectives, institutionalisation and distance between partners. Organizational factors seem to have a great relevance in the success of cooperation (Sánchez and Valentín, 2006). Trust between organizations is a very important factor in reducing barriers to $\mathrm{U}-\mathrm{I}$ interactions and argue that the traditional system of informal and reciprocal exchange is a central mechanism for initiating and building collaboration (Bruneel, D’Este and Salter, 2010).

Birchall and Chanaron (2006) state that common success factors are: common understanding and realistic expectations; problem solving in an open and joint manner; personal commitment on the part of the leaders of the parties; implementation of formal structures and processes for cooperation. Success of a partnership is linked to the needs of the industry and that its goals should be aligned with the joint goals and research objectives (Schofield, 2013).

Thus, in general, the literature points to the enormous relevance of communication and organizational factors, as a way to solve the cultural distancing of the two institutions (Garousi, et al., 2017).

\subsection{Researchers and students in cooperation}

PhD students are important actors in collaborative R\&D projects as they are important channels for knowledge transfer. PhD researchers may have a great impact on long-term benefits in companies(Thune, 2009). For their part, researchers are interested in economic and intellectual benefits, and companies are interested in longterm benefits, absorbing capabilities, and leveraging the results of research projects (De Fuentes and Dutrénit, 2012). The individual characteristics of researchers appear to be more important than those of the departments or universities from which they come. Their experience in previous collaborations makes them more likely to be involved in more future collaborations (D'Este and Patel, 2007).

\subsection{Cooperation management}

Most studies on U-I partnerships focus on the effects of cooperation, in particular measurable effects such as patents, and many other aspects remain to be explored, such as the results of the innovation process, whether at product or process level, and organisational dynamics (Perkmann, et al., 2013). 
Companies prefer cooperation over purely contractual forms when looking for more innovative products (VegaJurado, Kask and Manjarrés-Henriquez, 2017). Cooperation involves resource sharing, promotes the exchange and development of tacit knowledge and exposes heterogeneous knowledge. It is based on mutual learning and the company is interested not only in knowledge but also in the development of that knowledge. When products with a high degree of novelty are developed, many uncertainties and unpredictable paths may arise, and cooperation is a mechanism that allows ambiguities and adjustments during the R\&D process. Institutional interaction mechanisms are more appropriate for projects with high costs, low appropriability, and that focus on scientific knowledge of a more fundamental nature (Bodas Freitas, Geuna and Rossi, 2012). Factors related to the evaluation of partners, to communication, management of cultural differences, ensuring equality in the partnership and monitoring environmental influence were identified as important project management conditions in U-I collaboration (Barnes, Pashby and Gibbons, 2002).

\section{Methodology}

The research is based on a case study strategy. The case chosen for this study was the cooperation between the University of Minho (UMinho) and the company Bosch CarMultimedia (Bosch), both located in the city of Braga, Portugal. Bosch-CarMultimedia is a unit belonging to the Car Multimedia division based in Germany, which in turn belongs to the Bosch Group based in the same country (Robert Bosch SA, 2018). This unit is Bosch's main plant in Portugal, with more than 3300 employees in its ranks, including hundreds of engineers. The University of Minho is a young university founded in 1973 and currently has more than 1200 teachers and more than 600 employees, and about 20 thousand students spread over two poles. The University has teaching and research skills in all areas of scientific, literary and artistic knowledge.

The partnership between the two institutions began in 2012 and it was continued with another program which ended in 2018. Areas covered multimedia and infotainment solutions for car control panels, and the total investment was about 70 million euros, highly supported by Portuguese and European Union Structural funds.

The research approach is qualitative. Data was collected during 2018. In a first phase, documentary research was carried out. In a second phase primary data were obtained through participatory observations, informal conversations and through interviews with seven people. The interviews were semi-structured with common questions and with specific questions for each interviewee. The choice of respondents was made using two specific criteria. The people interviewed participated directly in the joint collaboration and held different hierarchical positions within the cooperation. Two top managers were interviewed (top in terms of the programme management), one from the company and one from the university, two middle managers, the socalled project managers, one from the university and one from the company, and three researchers, the lowest level, two from the university and one from the company.

\section{Analysis of results}

Due to lack of space it is not possible to present and treat all the questions and answers that were obtained. In all the topics several separate questions were asked, which will be dealt with here in a comprehensive way, choosing for presentation those that seem more important.

\subsection{Analysis of equality in partnership}

The issue of equality has to do with some aspects that were pointed out in the literature review, and that have to do with the objectives of each partner and the effectiveness of the collaboration. The respondents' answers all seem to point to the recognition that the company actually plays a predominant role in the collaboration.

The answers of the top executives is somewhat ambiguous. The company top executive side said that due to the size of the partnership there is no rule and "there are times when we accept that it is the side of UMinho that leads, other times we take the lead again, it depends on the day-to-day contingencies", so it gives the impression that the leadership is shared. The university top executive also tried to pass on the idea that there is equality, "I'm not saying that there is one leader more than the other, or one has more power than the other (...) we try to do is to understand where we can be complementary and at that time use knowledge, and experience to be complementary", however he also passes on the idea that they let themselves be led by the company by saying at the end of the answer that they try to achieve the goals that the company proposes to them. According to the company's project manager's opinion, there is not one idea of who dominates the other more, but rather of orientation, and he thinks that the company has a more important role in directing the ideas on the university 
side so that they make sense for the project. The university's project manager feels that leadership depends on the number of members of each team on both sides. If one team is much bigger than the other, it will probably lead more, although they have to be in line with the project requirement. At the last hierarchical level, to the researcher on the company side there is not much equality, and he says "UMinho ends up being a satellite of a company, the company is in charge of development and management (...) UMinho is able to influence with new discoveries, yes, that they can, but in political terms, of vision, of saying that this is the path we should follow, no, it is the company that decides". Their fellow researchers on the university side have a more neutral vision, saying that in their daily lives they do not feel these differences and that they have total freedom in doing their work.

Some of these opinions are in line with Schofield (2013) statement that, in addition to mutual trust, the factors contributing to the success of a partnership are the needs of the industry and its objectives should be aligned with the joint objectives and research objectives.

\subsection{Advantages of cooperation}

In a cooperation both parties must have advantages (Poyago-Theotoky, Beath and Siegel, 2002). On the top side of the company there was no doubt that the transfer of knowledge is the main advantage, followed by the proximity with researchers from the university and the capability to choose and hire the best, "we deal with researchers every day, we can quickly select those who are more top for the company (...) the great advantage is that we are in constant contact with the knowledge being used in universities". It partly confirms what Lam, Hills and Ng (2012) say when they argue that large companies are looking for information and technology from universities and staff for their executives. The university's top manager says this partnership has many advantages for the institution, as they have been able to improve the infrastructure, and buy and upgrade equipment. He also highlights the scientific benefits of publishing articles and registering patents, and also the contacts established by researchers who had very little experience in working with industry projects. This is in line with Lee (2000).

The university's project manager confirms the situation regarding employment, claiming not to have any students of his without a job offer. He also says that the visibility of UMinho and the inflow of money is one of the greatest advantages of this partnership. On the other hand, his partner on the company side emphasizes the contact with teachers and students and their added value, "they have contact with the industry and the company, with the scientific area, to have those new ideas, to have those innovative things that we typically only find here by our research or by benchmarking". This confirms companies' needs of external talent (Birchall and Chanaron, 2006).

For the university researchers the great advantage is that they have the opportunity to be up to date with what is done in the industry and create job opportunities. This opinion is also shared by the company's researcher saying "I think there's an added value in having a learning experience and updating what you're doing, and being on the crest of the technology wave, on top of that in a branch that is the future, is the present".

In the answers to this question it became evident that different levels of responsibility have different visions, with researchers having more individual, or more career, concerns.

\subsection{Define common objectives}

Respondents were asked if there were difficulties in defining and achieving common objectives. The answers were somewhat evasive, but showed that there were difficulties. This perception is confirmed in later questions that allow crossing the answers.

The company's top manager says: "Each one explains his part and in the end we create a common path, there may be some difficulties along the way, but which are quickly solved". On the other hand, the head of the university says, "We have everything. We have projects where Bosch's objectives are clear (...) we have others that Bosch is also not sure, it is not clear to Bosch what the objectives are". He thinks this is mainly due to a "lack of communication or understanding of what everyone wants". The literature emphasises this aspect, the need to agree on specific goals and agree jointly on what success means and how to achieve it, which requires a long and sustainable commitment and focus (Belfield, 2012). 
The project manager on the university side, despite having a more technical thought and vision at the level of objectives, spoke mainly of the influence of the parent company, i.e. Bosch in Germany. He says that all goals must be in line with the guidelines coming from Bosch in Germany, and that it becomes an enormous challenge to make it work. This same view is confirmed by the university researcher: "We started working together, we knew where we had to go and at some point we lost who we were working with and were left to work alone," referring to the fact that he started working with German teams; "we worked with this system for some time and then there was a break because there was a change of teams in Germany". The researcher felt concerned because he was used to a system where he had regular face-to-face meetings with local teams, and then changed to other communication channels, which made communication difficult and affected the understanding of the objectives. Communication is the factor that covers and brings together all the other factors, because it reinforces and strengthens them. Effective communication is imperative in a partnership as large as this one, and even more so when it involves three different cultures, which in this case are a business culture, an academic culture and a business culture of another country. Cultural and communication aspects are pointed out as essential (Schofield, 2013).

\subsection{Conflict/challenge management and the barriers to cooperation}

The company's top manager was perennial in stating that with so many people involved in such a large project, the difficulties were immense. He affirms that communication was one of the greatest challenges, saying "There are communication problems (...), we communicate in great detail, but we do not communicate what is really important". And what sometimes resolves these issues are the contractual obligations when he says: "What guides us in all this is that we have an investment contract, a consortium contract, (...) in the end all these conflicts, all these differences align themselves to fulfil what is there". He said that in a partnership it is positive to have collisions, discussions or disagreements, as long as the management can then control possible noises that may contaminate good relations. He ends by saying: "everything is chaotic, but everything is governable within this chaos".

The university's top manager also points out communication as a challenge because it involves so many people. However, he points out to the challenge of motivating researchers on a daily basis in order to achieve the objectives in the right time, which reveals the different stance between company and university regarding the time factor.

The company's top manager found other barriers and challenges, listing, for example, how to manage knowledge, manage payments, manage time, internal and external communication and the challenge of finding capable people and keep them: "Good minds are hired and then they finish the project and go to their lives, and then often to captivate those ideas and those big brains you have to wait a long time". This opinion is shared by both his university partner and the project managers of both entities.

For the company's project managers communication is also one of the biggest challenges, pointing out that the way to communicate with the academy has to be more careful, especially when they have to pass on the message that they are not on the best path. On the university side, as mentioned above, it is the fact that they have to deal with another entity - the mother house in Germany - a concern at the communication and cultural level. At the level of researchers, communication is a challenge or a difficulty, but technical and logistical issues are also problems to be solved. The different answers reflect particular hierarchical positions.

\subsection{Importance of Researchers}

Two questions were asked specifically to the researchers. One was whether they felt they valued them, and the other was whether they felt that some colleagues had already lost their initial enthusiasm. The researchers' answers were all along the same lines. They all take the view that they are not being given due and real value. One researcher says: "They don't give due value, not here and I don't think in most institutions, because they don't assure me of the necessary conditions not only for logistics but also for safety at work". He was referring to the precarious conditions of contracts, particularly of those who are at the university. This situation is not in line with what was said by those responsible for the collaboration or with what the literature addresses, which acknowledges that researchers are the key to an effective technology transfer (Barbolla and Corredera, 2009). When researchers were asked if they felt their colleagues had lost their initial enthusiasm, the company's researcher said, "Yes, but not in innovation. In development yes, many people, in innovation no." He also said that when they are creating something new "it's more fun" and it will be better for their careers, unlike those in 
"development" who are only meeting customer requirements. In other words, those who are doing less creative tasks get demotivated more easily.

As for the university's researchers, one of them says he has not noticed any of the aspects, because he wants to be successful in integrating himself to the industry after the event. Another says he has noticed a lack of enthusiasm and that some have left academic research to work in industry or continue in another area.

It may be concluded that there is some lack of sensitivity to these issues on the part of those at the top, i.e. there is no particular care to motivate these people to give them the importance they deserve, and which, paradoxically, is recognised by almost everyone.

\subsection{Analysis of the success of the partnership}

When asking about success factors, one expects an answer describing these factors, as some authors have done in the literature. However, for those responsible for this partnership it was simply the conclusion of the project. It seems reductive but it may be related to the somewhat exceptional and pioneering character of the collaboration for these two partners. The university's top manager mentions "the great success factor for us was to have already completed the project. It was the first time we've done a co-production project in Portugal". External recognition for the initiative and the results in publications or patents was also considered an important factor.

For project managers the answers are not so aligned. The university manager emphasized the results, the Bosch manager emphasized the team, saying "Team spirit! I think it's important. Or spirit of partnership, collaboration. Without that I think we start to lose, let's say, the vision of the goal and that in fact we are both entities - BoschUMinho - heading in the same direction". The response is aligned with literature that identifies common goals, understanding and teamwork as important factors for success (Garousi, et al., 2017).

The project results were at all hierarchical levels. However, the importance of teams was also mentioned. Among the researchers these items were mentioned, for example the company researcher said "The teams, quite simply the teams". Therefore, it could be said that for this group of people the success factors are not only the results, but also the teams, with their spirit and commitment. Common understanding, personal commitment and the implementation of formal structures and processes for cooperation are highlighted in the literature (Birchall and Chanaron, 2006).

\subsection{Improvements beyond success}

The questions on this subject were asked in order to understand what went less well in this partnership. The company's senior manager mentions the issue of teams again, confirming the perspective previously mentioned by the researchers "one has to improve the way to recognize the performance of the best teams (...) we are bad at recognizing the high performance of many teams, so communication, recognition given to the teams must improve". As pointed before, the characteristics of the researchers areveryimportant. He also mentions the kind of leadership for the future: "The world has changed radically, technologies are complex, but leadership is not keeping pace with these challenges. There are talents in the middle now, how leadership is going.... is another big area that needs to improve in the future". His counterpart on the university side highlighted more logistical and administrative aspects, but also aspects related to setting goals on the company side, citing "things to improve are in fact, I think, the goals Bosch has, i.e. what are its expectations in terms of project results. Hence, there is a lot of work to do on that, and I would say it is the responsibility of the Bosch side". The answer shows that the problems of communication and the setting of common goals did not go very well.

At the intermediate level, the project managers highlighted some logistical and administrative improvements, and the project manager on the company side highlighted (again) team spirit. He himself, in his daily experience, felt the diminishing of this spirit from one project to another. The university researchers referred to communication, and the precarious contractual situation in which they live. The company's researcher speaks of insufficient management's commitment to innovation in the company and that production is still by far the most important for the company. The management's commitment is referred to as an important factor in the literature (Garousi, et al., 2017). In short, at the various levels of responsibility perceptions varied, but the responses made it possible to consolidate and confirm some aspects mentioned before. 


\subsection{Analysis of the organizational model of collaboration}

The organizational structure of the collaboration may in some way be related to the success factors and difficulties mentioned. The head of the company side was asked if they had followed any examples from other partnerships to delineate the structure, in which he replied "there is nothing like it". Several questions were asked about this subject, to try to understand how they arrived at the organizational model adopted, and the interviewees were asked, for example, if this organizational structure (see Figure 1) would be ideal. The answer from the top manager of the company was: "It's not ideal, we have to innovate at the organizational level. (...) What is the ideal model? I don't know the answer to that question, I'd like to know, but I don't know". The answer seems to indicate that in this collaboration it was not easy to arrive at an interface governance model. Although the person in charge said that with this structure everyone knew exactly what they had to do, it does not seem to be enough to meet all the needs.

The head of the university answered "I think we are always adapting. We started with a structure in the first project,..., in the second we have already changed that structure and now we are thinking of changing it again". The structures have been changed from project to project, but it has not been possible to understand what and why these changes occurred.

When the same questions were asked to the project managers, the university's manager responded basically in line with his superiors, and his peer on the company side replied that the structure looks good, but that there were probably a few more project managers missing. For all three researchers, the structure worked well, although it is not possible to assess how important it is at their level.

\subsection{More on the organizational model of collaboration}

Studying the model of this collaboration, and without being able to compare it with any other model because nothing similar has been found in the studied literature, one can observe here a somewhat heavy structure with several hierarchical levels.

At the top of this structure is the Guidance and Inspection Board (GIB) whose function is to guide, supervise, control, establish the work plan, take decisions on any matter and decide disputes between consortium members. This council would be activated whenever necessary to resolve more serious situations, but it has never been necessary to meet for this function. It follows that conflicts were always resolved at lower levels. The council meets every 3 months, and is composed of the administrator of Bosch, the rector of UMinho and a third element, the Mayor of the city of Braga. At a second level we have the Steering Committee, composed of eleven members, seven of whom belong to Bosch and four to the University, and includes the two Directors of the company, the Rector and the two senior collaborators who participated in these interviews. Its function is to ensure the alignment of objectives, involvement and commitment, ensure the benefits and sustainability, aligned with the strategies of GIB. It is supported by the Innovation Management department, which monitors the results, ensures technology surveillance and knowledge management.

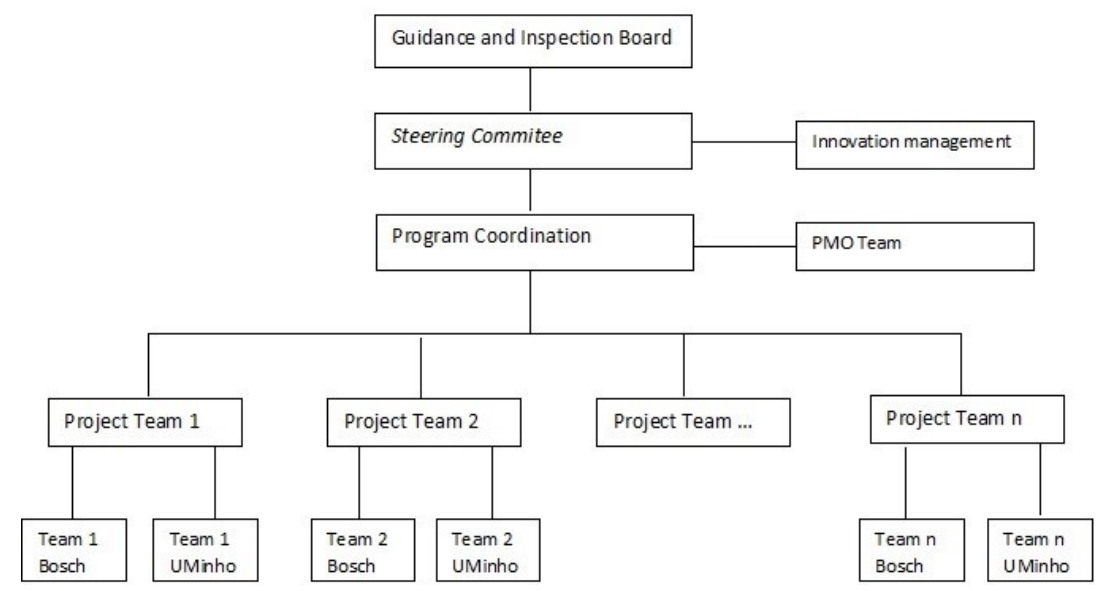

Figure 1: Organizational structure of collaboration

At the third level is the Program Coordination, consisting of six elements from the two institutions, three elements from the University and three from Bosch, and includes once again the two senior collaborators who 
participated in these interviews. The Program Coordination is the body which ensures the execution of everything that is deliberated and decided at the other higher levels. It is supported by another team (PMO Team) that ensures the information and communication part of the whole program. Next to this level come the research teams on both sides, with a team of Project Managers leading them. Two of these project managers were interviewed together with three researchers, who are at the last level of the hierarchy.

Given the relatively heavy, somewhat fragmented and mechanistically inspired structure, it is pertinent to ask whether the main problems encountered, namely those related to communication, the establishment of common objectives, team spirit, recognition of researchers, do not result from an organizational structure that is probably not the most appropriate for an innovation programme, which should favour a more organic posture and a more horizontal and fluid relationship between programme participants, even considering its size. The need for constant changes in the structure on the part of those responsible seems to indicate this difficulty.

\section{Conclusions}

Collaboration programmes between University and Industry in R\&D is a mechanism of knowledge transfer that has enormous advantages for these two institutions, although at the same time it is one of the most difficult to achieve. An important aspect to consider is the degree of involvement and commitment of partners. Partners should understand each other's objectives well, should commit themselves, but also have respect, understanding, mutual trust and effective communication. These are important items for success.

The main conclusions that can be drawn from this case study have to do with communication, which in turn relates to organizational aspects. Almost all respondents pointed out communication failures, reiterating that it is something that should be improved. Another aspect to be improved seems to be the valuation of researchers by both entities. Most of those involved also complained about the bureaucratic processes, which refers to the organizational structure adopted.

The organizational models in this type of collaboration can and probably should be somewhat flexible and dynamic and take into account the factors that have emerged more prominently from this study and the literature. The main conclusion and implication for future research of this exploratory study of a relatively large collaborative program between university and industry seems to be the need to understand in more detail the factors that favour organizational structures adapted to this type of collaboration. Literature is scarce on this topic, which seems to have a central importance in the functioning of the partnership.

\section{Acknowledgements}

This work has been supported by FCT - Fundação para a Ciência e Tecnologia within the R\&D Units Project Scope UIDB/00319/2020

\section{References}

Anatan, L. (2015) "Conceptual Issues in University to Industry Knowledge Transfer Studies: A Literature Review", Procedia Social and Behavioral Sciences, Vol 211, No. pp 711-717.

Barbolla, A. M. B. and Corredera, J. R. C. (2009) "Critical factors for success in university-industry research projects", Technology Analysis \& Strategic Management, Vol 21, No. 5, pp 599-616.

Barnes, T., Pashby, I. and Gibbons, A. (2002) "Effective University - Industry Interaction:: A Multi-case Evaluation of Collaborative R\&D Projects", European Management Journal, Vol 20, No. 3, pp 272-285.

Belfield, H. (2012) Making industry-university partnerships work: lessons from successful collaborations, Science|Business Innovation Board AISBL, Brussels.

Birchall, D. and Chanaron, J. (2006) "Business School-Industry Cooperation: Lessons from Case Studies", 2006 Technology Management for the Global Future - PICMET 2006 Conference, 8-13 July 2006,

Bodas Freitas, I. M., Geuna, A. and Rossi, F. (2012) "The governance of formal university-industry interactions: understanding the rationales for alternative models", Prometheus, Vol 30, No. 1, pp 29-45.

Bruneel, J., D’Este, P. and Salter, A. (2010) "Investigating the factors that diminish the barriers to university-industry collaboration", Research Policy, Vol 39, No. 7, pp 858-868.

D'Este, P. and Patel, P. (2007) "University-industry linkages in the UK: What are the factors underlying the variety of interactions with industry?", Research Policy, Vol 36, No. 9, pp 1295-1313.

De Fuentes, C. and Dutrénit, G. (2012) "Best channels of academia-industry interaction for long-term benefit", Research Policy, Vol 41, No. 9, pp 1666-1682. 
Garousi, V., Felderer, M., Fernandes, J. M., Pfahl, D. and Mäntylä, M. V. (2017) Industry-academia collaborations in software engineering: An empirical analysis of challenges, patterns and anti-patterns in research projects, Association for Computing Machinery, Karlskrona, Sweden.

Lam, J. C. K., Hills, P. and Ng, C. K. W. (2012) "Open Innovation: A Study of Industry- University Collaboration in Environmental R\&D in Hong Kong", International Journal of Technology, Knowledge \& Society, Vol 8, No. 6, pp 83-102.

Lee, Y. S. (2000) "The Sustainability of University-Industry Research Collaboration: An Empirical Assessment", The Journal of Technology Transfer, Vol 25, No. 2, pp 111-133.

Mussi, F., Pedroso, J. P. P. and Stoeckl, K. (2017) "UNIVERSITY-COMPANY COOPERATION IN A HYDROELECTRIC PLANT: COOPERATION STUDY IN ENVIRONMENTAL MANAGEMENT", Revista De Gestao Ambiental E Sustentabilidade-Geas, Vol 6, No. 1, pp 123-139.

Mussi, F. B. and Segatto, A. P. (2013) "Análise do instrumento de cooperação interinstitucional - Programa de Pesquisadores visitantes em Instituições de Ensino, pesquisa e/ou extensão", RAI Revista de Administração e Inovação, Vol 10, No. 3, pp 115-142.

Perkmann, M., Tartari, V., McKelvey, M., Autio, E., Broström, A., D’Este, P., Fini, R., Geuna, A., Grimaldi, R., Hughes, A., Krabel, S., Kitson, M., Llerena, P., Lissoni, F., Salter, A. and Sobrero, M. (2013) "Academic engagement and commercialisation: A review of the literature on university-industry relations", Research Policy, Vol 42, No. 2, pp 423442.

Poyago-Theotoky, J., Beath, J. and Siegel, D. S. (2002) "Universities and Fundamental Research: Reflections on the Growth of University-Industry Partnerships", Oxford Review of Economic Policy, Vol 18, No. 1, pp 10-21.

Sánchez, M. Á. M. and Valentín, E. M. M. (2006) "Hacia una gestión eficaz de las relaciones entre empresas y universidades", Universia Business Review, Vol No. 10, pp 38-53.

Schofield, T. (2013) "Critical Success Factors for Knowledge Transfer Collaborations between University and Industry", Journal of Research Administration, Vol 44, No. 2, pp 38-56.

Thune, T. (2009) "Doctoral students on the university-industry interface: a review of the literature", Higher Education, Vol 58, No. 5, pp 637.

Vega-Jurado, J., Kask, S. and Manjarrés-Henriquez, L. (2017) "University industry links and product innovation: cooperate or contract?", Journal of technology management \& innovation, Vol 12, No. pp 1-8.

Yegros-Yegros, A., Azagra-Caro, J. M., López-Ferrer, M. and Tijssen, R. J. W. (2016) "Do university-industry co-publication outputs correspond with university funding from firms?", Research Evaluation, Vol 25, No. 2, pp 136-150. 